\title{
The National Dementia Strategy: innovation or reiteration ${ }^{\dagger}$
}

\author{
Claire Hilton ${ }^{1}$
}

The Psychiatrist (2010), 34, 292-294, doi: 10.1192/pb.bp.109.025361

${ }^{1}$ Central and North West London NHS Foundation Trust, Harrow

Correspondence to Claire Hilton (claire.hilton@nhs.net)
Summary The National Dementia Strategy is based on constructive ideas to develop services for people with dementia, their families and carers. However, it is likely that this new strategy will have little impact because it is neither adequately funded nor mandatory. This opinion is based on patterns of implementation of healthcare policy in the UK over many years, especially that relating to the mental health needs of older people.

\section{Declaration of interests None.}

The week after the publication of the National Dementia Strategy $^{1}$ a brief report in the British Medical Journal quoted Health Secretary Alan Johnson as saying that it was a landmark document: 'It will transform the quality of dementia care'. ${ }^{2}$ Dementia care is without doubt an important and only partially met need. However, on calculating the resources committed to fulfilling this need, based on figures in the strategy (Box 1), the new money amounts to $0.5 \%$ of total dementia expenditure, less than the rate of inflation. Calculating it another way, it is approximately $£ 130$ per person with dementia in England per year. How Alan Johnson sees this as having the ability to transform the quality of care is unclear. Certainly, these are dire times for the economy but that is no excuse for claiming to do much more than is actually realistic.

\section{Health policies in the UK: the background}

Implementation of health policy in the UK has often been optional rather than mandatory. In addition, the more conflicts of interest there are, the longer it takes to establish change. This dilemma extends as far back as the Public Health Act 1848, introduced to improve urban sanitation. With that Act, optional recommendations were almost entirely ignored. The conflict of interest then was that the wealthy - voters, landlords and employers - would have to pay for the interventions to improve the living conditions of the poor. Significant progress was only made when proposals became mandatory under the 1872 Act. Similarly, in 1950 it was recognised that smoking was harmful to health, ${ }^{3}$ yet banning smoking in workplaces and enclosed public places in England only became mandatory in 2007. Again, conflicts of interest arose between tax gleaned by the government, the interests of the tobacco industry and the health of the population.

†See commentary, pp. 294-297, this issue.
Box 1 Cost of dementia care

- Total cost of dementia in the UK: $£ 17$ billion per year ${ }^{1}$

- England has approximately $84 \%$ of the UK population, therefore the cost of dementia in England is approximately $E 14.3$ billion

- Money offered is $E 150$ million in 2 years, which averages out at E75 million per year ${ }^{1}$

- As a percentage of total cost for dementia in England this new money is $0.52 \%$

\section{Mental health services provision for older people}

When we explore the needs of older people, negative stereotypes remain influential: that older people do not contribute to society, that they are a financial burden in a tsunami of increasing longevity and growing population, they cannot benefit from clinical intervention, etc. Such opinions are an inappropriate exaggeration but they have consistently influenced healthcare policy for older people, especially in mental health. What is the point, governments have constantly argued, in funding care for the elderly mentally ill, when other groups of society could benefit more? This idea had already become entrenched in the foundation of the welfare state and the National Health Service (NHS) in the UK with the publication of the Beveridge report in $1942{ }^{4}$ It stated: 'It is dangerous to be in any way lavish to old age, until adequate provision has been assured for all other vital needs'. It is only when service changes are defined as compulsory, such as the maximum of a 4-hour wait in accident and emergency departments, that they attract resources.

Planning for chronic degenerative disorders should be possible. But the apparent discovery by successive governments that the population of older people is increasing rapidly is repeatedly regarded with surprise. Such demographic changes are, of course, predictable. For older people, 
ideas which cost nothing abound, while financial commitment fades into obscurity.

\section{Evidence for lack of financial commitment}

Following the establishment of the NHS in 1948, the first innovative directive from the Ministry of Health to improve the well-being of mentally ill older people appeared in $1950 .^{5}$ It proposed psychogeriatric assessment units and accessible long-stay facilities. But it had a convenient optout clause: 'It is recognised that the present conditions of financial stringency limit opportunities for action at this time'. A new policy in 1970 largely reiterated the 1950 directive. $^{6}$ The government's apathy towards improving older people's care in those intervening 20 years has been well documented. ${ }^{7}$ Real progress came not from government, but from the enthusiasts around the country who pushed things forward.

In the 1980s, The Rising Tide was compiled by the Health Advisory Service in conjunction with clinicians. ${ }^{8}$ The government then offered an inadequate sum of money, not renewable, for the development of demonstration districts for old age psychiatry. The proposals for demonstration districts in 1982 very much parallel the terminology of the current national dementia strategy for demonstrator sites. As Arie \& Jolley commented in 1983, in response to The Rising Tide, "What we need is "development," and the fudging of the distinction between "development" and "demonstration" mars this important initiative." The same could be said today about the creative terminology of demonstrator sites. The 2009 dementia strategy has followed a model of good ideas with time-limited, insufficient financial commitment, as in 1982. Alison Norman commented in 1982 that people with dementia were 'commonly seen as a bottomless pit, swallowing up resources'. ${ }^{10}$ Using another metaphor, John Wattis wrote in 1987: 'This country can afford to spend more on healthcare; mentally ill old people need a larger slice of a larger cake not the crumbs left under the table after the other areas of medicine have fought over the dry crusts of present funding, ${ }^{11}$ The same fears and concerns are voiced today.

The absence of funding for mental health provision in the National Service Framework for Older People ${ }^{12}$ contrasts with significant funding attached to the National Service Framework for Mental Health, mainly for younger people. ${ }^{13}$ Further new funding for improving access to psychological therapies has so far largely been targeted at getting people of working age back into employment, ${ }^{14}$ rather than the ethically more acceptable approach of offering treatment on the basis of ability to benefit regardless of employment status or chronological age.

\section{A laissez-faire approach}

Mental healthcare for older people has made huge strides forwards, despite limited resources. However, older people's services lack components that are largely regarded as integral to the care of younger mentally ill people. These include crisis response and assertive outreach teams, acute hospital liaison ${ }^{15}$ and psychiatric intensive care units. Not infrequently, these new developments specifically exclude older people. ${ }^{16}$ In addition, it is quoted that for general adult mental health services 'The [World Health Organization] has said that England has the best services in Europe'. ${ }^{17}$ This contrasts with the provision of services for dementia as stated in the National Dementia Strategy: 'International comparisons suggest that the UK is in the bottom third of European performance in terms of diagnosis and treatment, with less than half the activity of France, Sweden, Ireland and Spain'. It is discriminatory to have such contrasts between services provided for mainly older people and those for mainly younger people.

With further demographic changes and increased longevity, the costs of dementia are predicted to treble in the next 30 years. ${ }^{1}$ The government, however, appears to have little belief in investing in a secure infrastructure for dementia in the light of this predicted service demand.

We are left with a strategy strong in ideas, although many of those can be dated back two decades or more, ${ }^{10}$ and like its predecessors, implementation is neither obligatory nor adequately funded, taking a laissez-faire stance. This attitude is summarised in the strategy itself: 'the pace of implementation will inevitably vary, depending on local circumstances and the level and development of services within each NHS and local authority area. Decisions on funding for subsequent years will only be made once we have had the opportunity to consider the results from the initial demonstrator sites and evaluation work. There is no expectation therefore that all areas will necessarily be able to implement the Strategy within five years.' This statement is unlikely to provoke ardent determination within commissioning bodies to achieve proposed goals.

One must also question the government's motivations when they offer only 2 years funding for a 5-year development plan, with funding dependent on the outcome of the progress made in the first 2 years. Experience suggests that the time required for most new projects to pass through the various mandatory commissionerprovider committees and then to recruit to new posts, 2 years will be too soon to evaluate the impact on care for a chronic disorder, especially where the individuals may be unable to contribute their own opinions.

\section{Conclusions}

I would like to be proved wrong, but the National Dementia Strategy is modelled on other failed strategies. It is neither mandatory nor sufficiently funded. Ideals of providing adequate, person-centred, humane care and support for people with dementia and their carers, and developing best quality services for the future (indeed, our future) will once more fail.

\section{Acknowledgements}

I thank Professor Tom Arie, Mrs Jean Gaffin, Dr Michael Hilton and Professor Dave Jolley for their comments. 


\section{About the author}

Claire Hilton is Consultant Old Age Psychiatrist, Central and North West London NHS Foundation Trust, Harrow.

\section{References}

1 Department of Health. Living Well with Dementia: A National Dementia Strategy. Department of Health, 2009.

2 Eaton L. Every town and city in England to have a memory clinic, says health secretary. BMJ 2009; 338: b464.

3 Doll R, Hill AB. Smoking and carcinoma of the lung: preliminary report. BMJ 1950; 2: 739-48.

4 Beveridge W. Social Insurance and Allied Services. HMSO, 1942.

5 Ministry of Health. Care of the Aged Suffering from Mental Infirmity. HMC(50)25, 1950 (typescript, King's Fund Library).

6 Department of Health and Social Security. Psycho-Geriatric Assessment Units. HM(70)71. HMSO, 1970.

7 Welshman J. Growing old in the city: Public health and the elderly in Leicester 1948-74. Med Hist 1996; 41: 74-89.

8 Dick DH. The Rising Tide - Developing Services for Mental IIIness in Old Age. National Health Service Health Advisory Service, 1982.
9 Arie T, Jolley D. 'The rising tide'. BMJ 1983; 286: 325-6.

10 Norman A. Mental Illness in Old Age: Meeting the Challenge. Centre for Policy on Ageing, 1982

11 Wattis JP. Working Party on the Care of the Elderly Mentally III. Recommendations for Service Development. Royal College of Psychiatrists, 1987.

12 Department of Health. National Service Framework for Older People. Department of Health, 2001

13 Philp I, Appleby L. Securing Better Mental Health for Older Adults. Department of Health, 2005.

14 Centre for Economic Performance's Mental Health Policy Group. The Depression Report: A New Deal for Depression and Anxiety Disorders. London School of Economics, 2006.

15 Faculty of Old Age Psychiatry, Royal College of Psychiatrists. Who Cares Wins: Guidelines for the Development of Liaison Mental Health Services for Older People. Royal College of Psychiatrists, 2005.

16 Department of Health. Mental Health Policy Implementation Guide: National Minimum Standards for General Adult Services in Psychiatric Intensive Care Units (PICU) and Low Secure Environments. Department of Health, 2002.

17 Appleby L. Mental Health Ten Years On: Progress on Mental Health Care Reform. Department of Health, 2007.

\section{National Dementia Strategy: a window of opportunity?}

\section{Commentary on ... National Dementia Strategy: innovation or reiteration? ${ }^{\dagger}$}

Steve lliffe $e^{1}$

The Psychiatrist (2010), 34, 294-297, doi: 10.1192/pb.bp.109.027094

Academic General Practitioner and Professor of Primary Care for Older People, University College London Correspondence to Steve Iliffe (s.iliffe@ucl.ac.uk)

\begin{abstract}
Summary Many practitioners will sympathise with Claire Hilton's views of the National Dementia Strategy. However, implementation of healthcare policies is frequently a long drawn out and messy process. There is no guarantee that its proposals will be implemented, given the vagaries of economies and the frailty of political will, but all of them could be. We should aim for gradual changes that produce qualitative shifts in the standards of dementia care.
\end{abstract}

Declaration of interest S.I. is Associate Director of the Dementias and Neurodegenerative Diseases Research Network and was a member of the External Reference Group of the National Dementia Strategy.
Claire Hilton makes very valid points about the National Dementia Strategy, ${ }^{1}$ and many practitioners will sympathise with them. However, we may need to adopt a long view of the potential of any current initiative, because the implementation of policy can have a long gestation. The

"See special article, pp. 292-294, this issue. polyclinics now appearing in England were first mooted in the Dawson Report of 1920. The National Health Service (NHS) - as a system of medical care free at the time of need - began to appear in 1911 with the creation of the 'panel' that gave men of working age free access to general practitioners. Free access to medical services extended gradually and in piecemeal ways so that two-thirds of the population was receiving generalist and some specialist 